\title{
Profile Matching Untuk Sistem Pendukung Keputusan Penilaian Kinerja Driver
}

\author{
Achmad Wahid Kurniawan ${ }^{1}$, Budi Widjajanto ${ }^{2}$, Ida Farida ${ }^{3}$ \\ ${ }^{1}$ Teknik Informatika/Universitas Dian Nuswantoro \\ Jl. Nakula I No. 5 - 11 Semarang, e-mail: wahid@dsn.dinus.ac.id \\ 2 Sistem Informasi/Universitas Dian Nuswantoro \\ JI. Nakula I No. 5 - 11 Semarang, e-mail: budi.widjajanto@dsn.dinus.ac.id \\ ${ }^{3}$ Manajemen / Universitas Dian Nuswantoro \\ JI. Nakula I No. 5 - 11 Semarang, e-mail: ida.farida@dsn.dinus.ac.id
}

\section{ARTICLE INFO}

Article history:

Received 17 February 2021

Received in revised form 26 July 2021

Accepted 31 July 2021

Available online 31 July 2021

\begin{abstract}
ABSTRAK
Periodic assessments of drivers need to be carried out, to evaluate performance. Evaluation takes time so that evaluations are often carried out when complaints from passengers occur, giving the effect of temporary changes as well, after the complaints are resolved, the drivers and transportation division leaders assume that there will not be another incident that happened. same. This study aims to make a decision support system regarding a modeled and comprehensive performance appraisal of all drivers, which is periodic with the Profile Matching method. The final results obtained are really based on the performance value that comes from the performance of each driver.
\end{abstract}

Keywords: Decision Support System, performance, driver, profile matching

\section{Pendahuluan}

Sarana berupa kendaraan yang mampu memberikan peran penting dalam pemenuhan kebutuhan manusia adalah transportasi [1]. Faktor keselamatan dari sebuah tranfortasi adalah elemen utama yang harus diperhatikan dalam standar operasional pemakaian, dimana driver sebagai pemegang utama faktor tersebut.

Penilaian secara periodik terhadap driver perlu dilakukan, untuk mengevaluasi kinerja. Pelaksanaan evaluasi membutuhkan waktu sehingga evaluasi sering dilakukan saat terjadi keluhan dari penumpang saja, memberikan efek perubahan yang sifatnya sementara juga, setelah keluhan teratasi maka driver maupun pimpinan divisi transportasi menganggap tidak akan terjadi lagi kejadian yang sama.

Selanjutnya dikembangkan sistem penilaian kinerja yang termodel dan menyeluruh terhadap semua driver yang sifatnya periodik, sehingga akan mampu meminimalisir kejadikan yang dikeluhkan penumpang. Penilaian didasarkan pada beberapa variabel yang dapat digali dari setiap driver, diantaranya kemampuan komunikasi, tingkat emosional, gaya mengemudi, jumlah kecelakaan, jumlah pelanggaran, ketepatan waktu, tanggung jawab, umur dan kejujuran.Dari Received February 17, 2021; Revised July 26, 2021; Accepted July 31, 2021 
beberapa variabel tersebut dapat dikategorikan dalam faktor kelompok, seperti kemampuan komunikasi dan faktor situasi, berupa tinggi datau rendahnya tekanan yang membawa pada perubahan di dalam dan di luar lingkungan kerja seeprti jumlah kecelakaan dan jumlah kecelakaan [2].

Sistem pendukung keputusan akan melakukan penilaian dengan saling mengaitkan semua variabel yang ada. Pada penelitian ini menggunakan metode profile matching sebagai metode perhitungan. Metode ini menganut pengambilan keputusan secara multi variabel dengan mengandung unsur tujuan dan obyektif [3].Sistem pendukung keputusan belum tentu mengotomatisasi pengambilan sebuah keputusan namun memberikan interface bagi pengambil keputusan dalam melakukan proses analisis dengan model yang tersedia [4]. Tujuan dari sistem oendukung keputusan adalah menjadi alat yang mampu membantu pihak pengambil keputusan dalam tanpa meninggalkan penilaian [5]. Penelitian ini bertujuan menghasilkan hasil penilaian kinerja driver yang sesuai dengan kombinasi variabel penilaian yang telah ditentukan.

\section{Metode Penelitian}

\subsection{Metode Pengumpulan Data}

Metode pengumpulan data yang digunakan penelitian ini meliputi observasi,dengan pengumpulan data melalui pengambilan sejumlah data kinerja driver melalui kepala sub bagian transportasi.

\subsection{Metode Penilaian}

Metode Pengambilan keputusan yang digunakan adalah profile matching. Metode ini di mulai dengan penentuan variabel yang digunakan serta menentukakan nilai standar dari tiap-tiap variabel [6]. Selanjutnya dilakukan perhitungan dengan core factor dan secondary factor yang sebelumnya telah ditentukan prosentase sebelumnya [7]. Berikut adalah tahapan profile matching [8]:

1. Identifikasi variabel penilaian

Variabel ditentukan oleh pihak pengambil keputusan, pada penelitian ini ditentukan oleh kepala transportasi.

2. Penentuan nilai standar setiap variabel

Nilai standar juga ditentukan oleh pihak pengambil keputusan, pada penelitian ini ditentukan oleh kepala transportasi .

3. Memasukkan nilai setiap obyek

Nilai setiap obyek diinputkan berdasarkan nilai yang kinerja masing-masing obyek yang dinilai.

4. Penentuan GAP

Gap merupakan selisih nilai dari point 2 dikurangi point 3

Gap $=$ profil obyek - profil nilai standar

5. Pembobotan

Setelah gap diperoleh selanjutnya dilakukan pembobotan berdasarkan tabel bobot. [9]

Tabel 1. Tabel Pembobotan

\begin{tabular}{lll}
\hline Gap & Bobot Nilai & Ketrangan \\
\hline 0 & 5 & Kompetensi sesuai yang dibutuhkan \\
1 & 4,5 & $\begin{array}{l}\text { Kompetensi obyek kelebihan 1 } \\
\text { tingkat/level }\end{array}$
\end{tabular}

Profile Matching Untuk Sistem Pendukung Keputusan Penilaian Driver (Achmad Wahid 


\begin{tabular}{|c|c|c|}
\hline-1 & 4 & Kompetensi obyek kurang 1 tingkat/level \\
\hline 2 & 3,5 & $\begin{array}{l}\text { Kompetensi obyek kelebihan } 2 \\
\text { tingkat/level }\end{array}$ \\
\hline-2 & 3 & Kompetensi obyek kurang 2 tingkat/level \\
\hline 3 & 2,5 & $\begin{array}{l}\text { Kompetensi obyek kelebihan } 3 \\
\text { tingkat/level }\end{array}$ \\
\hline-3 & 2 & Kompetensi obyek kurang 3 tingkat/level \\
\hline 4 & 1,5 & $\begin{array}{l}\text { Kompetensi obyek kelebihan } 4 \\
\text { tingkat/level }\end{array}$ \\
\hline-4 & 1 & Kompetensi obyek kurang 4 tingkat/level \\
\hline
\end{tabular}

6. Core factor dan Secondary factor Variabel utama disebut Core factor sedangkan variabel pendukung disebut sebagai secondary factor. Yang menentukan variabel kedalam kelompok Core factor atau secondary factor adalah pihak pengambil keputusan, dalam hal ini kepala transportasi [10].

Keterangan rumus :

$$
N C F=\frac{\sum N C}{\sum I C}
$$

$\mathrm{NCF}=$ Nilai rata-rata Core Factor

$\mathrm{NC}=$ Jumlah total nilai core factor

$\mathrm{IC}=$ jumlah item nilai core factor

$$
N S F=\frac{\sum N S}{\sum I S}
$$

Keterangan rumus :

NSF = Nilai rata-rata Secondary Factor

$\mathrm{NS}=$ Jumlah total nilai Secondary factor

IS = jumlah item nilai secondary factor

7. Nilai Akhir

Masing-masing nilai baik core factor maupun secondary factor memiliki bobot persentase. Nilai akhir diperoleh dengan nilai persentase tersebut terhadap NCF dan NSF [11].

Nilai Akhir $=a(\%) \times N C F+b(\%) \times N S F$

\section{Hasil dan Pembahasan}

\subsection{Bobot Capaian Setiap Variabel}

Bobot setiap variabel bisa diatur besarnya [12] , tinggal disesuaikan kepentingan penilaian yang sudah ditentukan oleh kepala transportasi, misalkan dalam implementasi diberikan nilai bobot sebagai berikut :

Tabel 2. Nilai capaian

\begin{tabular}{lll}
\hline Jenis Variabel & $\begin{array}{l}\text { Nilai } \\
\text { Bobot }\end{array}$ & Keterangan \\
\hline
\end{tabular}

TRANSFORMATIKA Vol. 19, No. 1, July 2021: $74-83$ 
Kemampuan Komunikasi 3

$\left(\mathrm{A}_{1}\right)$

Tingkat Emosional $\left(\mathrm{A}_{2}\right)$

Gaya Mengemudi $\left(\mathrm{A}_{3}\right)$

Jumlah Kecelakaan $\left(\mathrm{A}_{4}\right)$

Jumlah Pelanggaran $\left(\mathrm{A}_{5}\right)$
1:Tidak memenuhi, tidak mampu berkomunikasi terhadap penumpang

2:Kurang, kurang mampu berkomunikasi terhadap penumpang

3.Cukup, cukup mampu berkomunikasi dengan penumpang

4.Baik, Mampu berkomunikasi dengan penumpang

5.Sangat baik, Sangat mampu berkomunikasi dengan penumpang

$4 \quad$ 1.Tidak memenuhi, tidak mampu mengendalikan emosi

2.Kurang, kurang mampu dalam mengendalikan emosi

3.Cukup, cukup mampu dalam mengendalikan emosi

4.Baik, mampu dalam pengendalian emosi

5.Sangat baik, sangat mampu dalam mengendalikan emosi

$4 \quad$ 1.Tidak memenuhi, gaya mengemudi tidak memberi rasa nyaman penumpang

2.Kurang, gaya mengemudi kurang memberi rasa nyaman penumpang

3.Cukup, gaya mengemudi cukup memberi rasa nyaman penumpang

4.Baik, gaya mengemudi memberi rasa nyaman penumpang

5.Sangat baik, gaya mengemudi sangat memberi rasa nyaman penumpang

1.Tidak memenuhi, sering melakukan tindakan yang menyebabkan kecelakaan

2.Kurang, jarang melakukan tindakan yang menyebabkan kecelakaan

3.Cukup, pernah terjadi kecelakaan yang tidak disengaja

4.Baik, berhati-hati dan tidak pernah terjadi kecelakaan

5.Sangat Baik, sangat berhati-hati dan tidak pernah terjadi kecelakaan

1.Tidak memenuhi, sering melakukan pelanggaran lalu lintas

2.Kurang, jarang melakukan pelanggaran lalu linas

3.Cukup, pernah melakukan pelanggaran

4.Baik, berhati-hati dan tidak pernah melakukan pelanggaran 
Ketepatan waktu $\left(\mathrm{A}_{6}\right)$

Tanggung Jawab $\left(\mathrm{A}_{7}\right)$

$\operatorname{Umur}\left(\mathrm{A}_{8}\right)$

Kejujuran $\left(A_{9}\right)$
4

5

5.Sangat Baik, sangat berhati-hati dan tidak pernah melakukan pelanggaran

1.Tidak memenuhi, hampir terlambat setiap hari

2.Kurang, sering terlambat

3.Cukup, pernah terlambat

4.Baik, tidak pernah terlambat

5.Sangat Baik, tepat waktu

1.Tidak memenuhi, tidak pernah bertnggung jawab

2.Kurang, kurang mampu bertanggung jawab

3.Cukup, cukup mampu bertanggung jawab

4.Baik, mampu bertanggung jawab

5.Sangat Baik, sangat bertanggung jawab

1.Tidak memenuhi, 22 sampai 25 tahun

2.Kurang, >45 tahun

3.Cukup, 26 sampai 34 tahun

4.Baik,35 sampai 40 tahun

5.Sangat Baik, 41 sampai 45 tahun

1.Tidak memenuhi, tidak jujur

2.Kurang, kurang jujur

3.Cukup, cukup jujur

4.Baik,jujur

5.Sangat Baik, sangat jujur

\subsection{Pendataan Kinerja Driver}

Berikut disajikan data sample dari kinerja semua driver yang diambil dari dari data penelitian ini

Tabel 3. Nilai kinerja driver

\begin{tabular}{|l|l|l|l|l|l|l|l|l|l|l|}
\hline No. & \multirow{2}{*}{ Driver } & \multicolumn{9}{|c|}{ Variabel Penilaian } \\
\cline { 3 - 13 } & & $\mathrm{A}_{1}$ & $\mathrm{~A}_{2}$ & $\mathrm{~A}_{3}$ & $\mathrm{~A}_{4}$ & $\mathrm{~A}_{5}$ & $\mathrm{~A}_{6}$ & $\mathrm{~A}_{7}$ & $\mathrm{~A}_{8}$ & $\mathrm{~A}_{9}$ \\
\hline 1 & Agus & 5 & 5 & 4 & 3 & 4 & 2 & 5 & 2 & 4 \\
\hline 2 & Ali & 5 & 3 & 3 & 4 & 3 & 4 & 4 & 5 & 3 \\
\hline 3 & Amat & 3 & 5 & 5 & 5 & 5 & 5 & 5 & 3 & 4 \\
\hline 4 & Didik & 4 & 3 & 4 & 4 & 4 & 4 & 4 & 3 & 4 \\
\hline 5 & Rohman & 3 & 4 & 5 & 4 & 4 & 4 & 4 & 2 & 4 \\
\hline 6 & Rubby & 3 & 3 & 3 & 4 & 3 & 4 & 4 & 5 & 3 \\
\hline 7 & Wahyu & 4 & 5 & 2 & 4 & 4 & 4 & 4 & 4 & 4 \\
\hline 8 & Yanto & 2 & 3 & 4 & 5 & 5 & 5 & 4 & 5 & 4 \\
\hline
\end{tabular}

\subsection{Perhitungan Profile Matching}


Gap dimaksudkan untuk mencari selisih antara profile nilai kinerja driver (tabel 3) dengan profile nilai capaian (tabel 2), dimana nilai GAP diperoleh dari selisih profile nilai kinerja driver dengan profil nilai capaian

Tabel 4. Pemetaan GAP

\begin{tabular}{|l|l|l|l|l|l|l|l|l|l|l|}
\hline \multirow{2}{*}{ No. } & \multirow{2}{*}{ Driver } & \multicolumn{9}{|c|}{ Variabel Penilaian } \\
\cline { 3 - 13 } & & $\mathrm{A}_{1}$ & $\mathrm{~A}_{2}$ & $\mathrm{~A}_{3}$ & $\mathrm{~A}_{4}$ & $\mathrm{~A}_{5}$ & $\mathrm{~A}_{6}$ & $\mathrm{~A}_{7}$ & $\mathrm{~A}_{8}$ & $\mathrm{~A}_{9}$ \\
\hline 1 & Agus & 5 & 5 & 4 & 3 & 4 & 2 & 5 & 2 & 4 \\
\hline 2 & Ali & 5 & 3 & 3 & 4 & 3 & 4 & 4 & 5 & 3 \\
\hline 3 & Amat & 3 & 5 & 5 & 5 & 5 & 5 & 5 & 3 & 4 \\
\hline 4 & Didik & 4 & 3 & 4 & 4 & 4 & 4 & 4 & 3 & 4 \\
\hline 5 & Rohman & 3 & 4 & 5 & 4 & 4 & 4 & 4 & 2 & 4 \\
\hline 6 & Rubby & 3 & 3 & 3 & 4 & 3 & 4 & 4 & 5 & 3 \\
\hline 7 & Wahyu & 4 & 5 & 2 & 4 & 4 & 4 & 4 & 4 & 4 \\
\hline 8 & Yanto & 2 & 3 & 4 & 5 & 5 & 5 & 4 & 5 & 4 \\
\hline & & $\mathbf{3}$ & $\mathbf{4}$ & $\mathbf{4}$ & $\mathbf{4}$ & $\mathbf{4}$ & $\mathbf{4}$ & $\mathbf{5}$ & $\mathbf{4}$ & $\mathbf{5}$ \\
\hline 1 & Agus & 2 & 1 & 0 & -1 & 0 & -2 & 1 & -2 & 0 \\
\hline 2 & Ali & 2 & -1 & -1 & 0 & -1 & 0 & 0 & 1 & -1 \\
\hline 3 & Amat & 0 & 1 & 1 & 1 & 1 & 1 & 1 & -1 & 0 \\
\hline 4 & Didik & 1 & -1 & 0 & 0 & 0 & 0 & 0 & -1 & 0 \\
\hline 5 & Rohman & 0 & 0 & 1 & 0 & 0 & 0 & 0 & -2 & 0 \\
\hline 6 & Rubby & 0 & -1 & -1 & 0 & -1 & 0 & 0 & 1 & -1 \\
\hline 7 & Wahyu & 1 & 1 & -2 & 0 & 0 & 0 & 0 & 0 & 0 \\
\hline 8 & Yanto & -1 & -1 & 0 & 1 & 1 & 1 & 0 & 1 & 0 \\
\hline
\end{tabular}

\section{Pembobotan}

Hasil dari selisih nilai kinerja driver dan nilai capaian, selanjutnya dibobotkan sesuai dengan tabel 1., sehingga selanjutnya diperoleh hasil pembobotan sebagai berikut

Tabel 5. Tabel hasil pembobotan

\begin{tabular}{|l|l|l|l|l|l|l|l|l|l|l|}
\hline \multirow{2}{*}{ No. } & \multirow{2}{*}{ Driver } & \multicolumn{9}{|c|}{ GAP dari Variabel Penilaian } \\
\cline { 3 - 13 } & & $\mathrm{A}_{1}$ & $\mathrm{~A}_{2}$ & $\mathrm{~A}_{3}$ & $\mathrm{~A}_{4}$ & $\mathrm{~A}_{5}$ & $\mathrm{~A}_{6}$ & $\mathrm{~A}_{7}$ & $\mathrm{~A}_{8}$ & $\mathrm{~A}_{9}$ \\
\hline 1 & Agus & 2 & 1 & 0 & -1 & 0 & -2 & 1 & -2 & 0 \\
\hline 2 & Ali & 2 & -1 & -1 & 0 & -1 & 0 & 0 & 1 & -1 \\
\hline 3 & Amat & 0 & 1 & 1 & 1 & 1 & 1 & 1 & -1 & 0 \\
\hline 4 & Didik & 1 & -1 & 0 & 0 & 0 & 0 & 0 & -1 & 0 \\
\hline 5 & Rohman & 0 & 0 & 1 & 0 & 0 & 0 & 0 & -2 & 0 \\
\hline 6 & Rubby & 0 & -1 & -1 & 0 & -1 & 0 & 0 & 1 & -1 \\
\hline 7 & Wahyu & 1 & 1 & -2 & 0 & 0 & 0 & 0 & 0 & 0 \\
\hline 8 & Yanto & -1 & -1 & 0 & 1 & 1 & 1 & 0 & 1 & 0 \\
\hline & & \multicolumn{7}{|c|}{ Nilai Hasil Pembobotan } \\
\hline 1 & Agus & 3.5 & 4.5 & 5 & 4 & 5 & 3 & 4.5 & 3 & 5 \\
\hline 2 & Ali & 3.5 & 4 & 4 & 5 & 4 & 5 & 5 & 4.5 & 4 \\
\hline 3 & Amat & 5 & 4.5 & 4.5 & 4.5 & 4.5 & 4.5 & 4.5 & 4 & 5 \\
\hline 4 & Didik & 4.5 & 4 & 5 & 5 & 5 & 5 & 5 & 4 & 5 \\
\hline 5 & Rohman & 5 & 5 & 4.5 & 5 & 5 & 5 & 5 & 3 & 5 \\
\hline \hline
\end{tabular}




\begin{tabular}{|l|l|l|l|l|l|l|l|l|l|l|}
\hline 6 & Rubby & 5 & 4 & 4 & 5 & 4 & 5 & 5 & 4.5 & 4 \\
\hline 7 & Wahyu & 4.5 & 4.5 & 3 & 5 & 5 & 5 & 5 & 5 & 5 \\
\hline 8 & Yanto & 4 & 4 & 5 & 4.5 & 4.5 & 4.5 & 5 & 4.5 & 5 \\
\hline
\end{tabular}

\section{Perhitungan Core Factor dan Secondary Factor}

Dari Sembilan variabel yaitu Kemampuan Komunikasi $\left(\mathrm{A}_{1}\right)$, Tingkat Emosional $\left(\mathrm{A}_{2}\right)$, Gaya Mengemudi $\left(A_{3}\right)$, Jumlah Kecelakaan $\left(A_{4}\right)$, Jumlah Pelanggaran $\left(A_{5}\right)$, Ketepatan waktu $\left(A_{6}\right)$, Tanggung Jawab $\left(\mathrm{A}_{7}\right)$, Umur $\left(\mathrm{A}_{8}\right)$, Kejujuran $\left(\mathrm{A}_{9}\right)$. Selanjutnya akan di pecah menjadi dua kelompok variabel yaitu core factor dan secondary factor.

Pengelompokan kelompok pertama adalah core factor, merupakan kelompok variabel yang dominan atau penting dalam proses perhitungan [13], yang masuk dalam kategori core factor adalah Kemampuan Komunikasi $\left(\mathrm{A}_{1}\right)$, Tingkat Emosional $\left(\mathrm{A}_{2}\right)$, Gaya Mengemudi $\left(\mathrm{A}_{3}\right)$, Jumlah Kecelakaan $\left(\mathrm{A}_{4}\right)$, Jumlah Pelanggaran $\left(\mathrm{A}_{5}\right)$, Ketepatan waktu $\left(\mathrm{A}_{6}\right)$. Untuk mencari nilai core factor digunakan rumus sebegai berikut :

$$
N C F=\frac{\Sigma \mathrm{NC}}{\sum \mathrm{IC}}
$$

Keterangan : NCF : Nilai core factor, NC : Jumlah total nilai core factor, IC : jumlah variabel core factor.

Pengelompokan kedua adalah secondary factor, merupakan variabel pendukung dari core factor [14], yang masuk dalam kategori ini adalah Tanggung Jawab $\left(\mathrm{A}_{7}\right)$, Umur $\left(\mathrm{A}_{8}\right)$, Kejujuran $\left(\mathrm{A}_{9}\right)$

$$
N S F=\frac{\sum \text { NS }}{\sum \text { IS }}
$$

Keterangan : NSF : Nilai Secondary factor, NS: Jumlah total nilai secondary factor, IS : jumlah variabel secondary factor.

Tabel 6. Tabel NCF dan NSF

\begin{tabular}{|l|l|l|l|l|l|l|l|l|l|l|l|l|}
\hline \multirow{2}{*}{ No. } & \multirow{2}{*}{ Driver } & \multicolumn{7}{|c|}{ Nilai Hasil Pembobotan } & \multicolumn{2}{|c|}{ NCF } & NSF \\
\cline { 3 - 13 } & & $\mathrm{A}_{1}$ & $\mathrm{~A}_{2}$ & $\mathrm{~A}_{3}$ & $\mathrm{~A}_{4}$ & $\mathrm{~A}_{5}$ & $\mathrm{~A}_{6}$ & $\mathrm{~A}_{7}$ & $\mathrm{~A}_{8}$ & $\mathrm{~A}_{9}$ & & \\
\hline 1 & Agus & 3.5 & 4.5 & 5 & 4 & 5 & 3 & 4.5 & 3 & 5 & $\begin{array}{l}=\frac{3.5+4.5+5+4+5+3}{=4.2} \\
=\end{array}$ & $\begin{array}{l}4.5+3+5 \\
=4.2\end{array}$ \\
\hline 2 & Ali & 3.5 & 4 & 4 & 5 & 4 & 5 & 5 & 4.5 & 4 & 4.3 & 4.5 \\
\hline 3 & Amat & 5 & 4.5 & 4.5 & 4.5 & 4.5 & 4.5 & 4.5 & 4 & 5 & 4.6 & 4.5 \\
\hline 4 & Didik & 4.5 & 4 & 5 & 5 & 5 & 5 & 5 & 4 & 5 & 4.8 & 4.7 \\
\hline 5 & Rohman & 5 & 5 & 4.5 & 5 & 5 & 5 & 5 & 3 & 5 & 4.9 & 4.5 \\
\hline 6 & Rubby & 5 & 4 & 4 & 5 & 4 & 5 & 5 & 4.5 & 4 & 4.5 & 5.0 \\
\hline 7 & Wahyu & 4.5 & 4.5 & 3 & 5 & 5 & 5 & 5 & 5 & 5 & 4.5 & 4.8 \\
\hline 8 & Yanto & 4 & 4 & 5 & 4.5 & 4.5 & 4.5 & 5 & 4.5 & 5 & 4.4 & \\
\hline
\end{tabular}

\section{Perolehan Nilai Total}

Perolehan nilai total dapat diperoleh dari rumus [15],

TRANSFORMATIKA Vol. 19, No. 1, July 2021: $74-83$ 


$$
\mathrm{N}=(\mathrm{x} \%) \mathrm{NCF}+(\mathrm{y} \%) \mathrm{NSF}
$$

$\mathrm{x} \%$ dan $\mathrm{y} \%$ dapat diatur persentasenya, tergantung pihak pengambil keputusan selaku user, missal ditetapkan $\mathrm{x} \%=60 \%$ dan y $\%=40 \%$, maka nilai total akan dihasilkan sebagai berikut :

Tabel 7. Tabel Nilai Total

\begin{tabular}{|l|l|l|l|l|}
\hline No. & Driver & \multicolumn{1}{|c|}{ NCF } & NSF & $\begin{array}{l}\text { Nilai } \\
\text { Total }\end{array}$ \\
\hline 1 & Agus & 4.2 & 4.2 & 4.2 \\
\hline 2 & Ali & 4.3 & 4.5 & 4.4 \\
\hline 3 & Amat & 4.6 & 4.5 & 4.6 \\
\hline 4 & Didik & 4.8 & 4.7 & 4.7 \\
\hline 5 & Rohman & 4.9 & 4.3 & 4.7 \\
\hline 6 & Rubby & 4.5 & 4.5 & 4.5 \\
\hline 7 & Wahyu & 4.5 & 5.0 & 4.7 \\
\hline 8 & Yanto & 4.4 & 4.8 & 4.6 \\
\hline
\end{tabular}

\section{Hasil akhir adalah dengan perangkingan nilai total}

Tabel 8. Tabel Hasil setelah dirangking

\begin{tabular}{|l|l|c|}
\hline No. & Driver & $\begin{array}{c}\text { Nilai } \\
\text { Total }\end{array}$ \\
\hline 1 & Didik & 4.7 \\
\hline 2 & Rohman & 4.7 \\
\hline 3 & Wahyu & 4.7 \\
\hline 4 & Amat & 4.6 \\
\hline 5 & Yanto & 4.6 \\
\hline 6 & Rubby & 4.5 \\
\hline 7 & Ali & 4.4 \\
\hline 8 & Agus & 4.2 \\
\hline
\end{tabular}

Berdasarkan tabel 8. diatas, penentuan driver dengan kinerja terbaik diambil dari nilai total tertinggi tertinggi, namun jika nilai tertinggi dimiliki oleh beberapa driver, misalkan terdapat 3 driver dengan nilai terbaik maka pihak pengambil keputusan berhak memilih dari ketiganya.

\section{Kesimpulan}

Penilaian kinerja driver menggunakan metode profile matching sangat membantu memberikan keputusan bagi pihak pengambil keputusan dalam menghasilkan keputusan yang berorientasi objek, sehingga hasil akhir yang didapatkan benar-benar berdasarkan nilai kinerja yang bersumber dari kinerja masing-masing driver.

Profile Matching Untuk Sistem Pendukung Keputusan Penilaian Driver (Achmad Wahid 
Dengan adanya hasil penilaian ini, maka driver dengan peringkat dibawah dapat ditingkatkan kinerjanya melalui peningkatan pada semua unsur atau variabel penilaian.

\section{Daftar Pustaka}

[1] P. C. Giri, "Analisis Faktor-Faktor Yang Mempengaruhi Pendapatan Driver Go-Jek Di Kota Denpasar, Bali," E-Jurnal EP Unud, vol. 6, pp. 948-975, 2017.

[2] U. W. Lailiyah, "Analisis Faktor-Faktor Yang Mempengaruhi Kinerja Driver Grab-Bike Kabupaten Banjarnegara," Jurnal Manajemen dan Bisnis MEDIA EKONOMI, vol. 19, Januari 2019.

[3] A. Sudarmadi, "Sistem Pendukung Keputusan Pemilihan Personel Homeband Universitas Brawijaya Menggunakan Metode Profile Matching," Jurnal Pengembangan Teknologi Informasi dan Ilmu Komputer, vol. 1, pp. 17881796, Desember 2017.

[4] E. "Rancang Bangun Sistem Pendukung Keputusan Kenaikan Jabatan Pegawai Dengan Metode Profile Matching," Studia Informatika, pp. 128-134, 2017.

[5] I. A. Wicaksono, "Sistem Pendukung Keputusan Kenaikan Jabatan Struktural Dengan Metode Profile Matching Pada Karyawan Universitas Negeri Semarang," Jurusan Teknik Elektro Universitas Semarang, 2017.

[6] F. Adam, "Pemilihan Karyawan Terbaik Menggunakan Metode Profile MAtching Pada PT. Surindo Murni Agung," Jurnal Infortech, vol. 1, pp. 2127, Juni 2019.

[7] A. A. Tri Susilo, "Penerapan Metode Profile Matching Pada Sistem Pendukung Keputusan Pemilihan Ketua Program Studi (Studi Kasus Program Studi Teknik Informatika STMIK Musi Rawas)," JUITA, vol. 5, pp. 87-93, November 2017.

[8] H. Purwanto, "Penerapan Metode Profile Matching Dalam Sistem Pendukung Keputusan Penilaian Kinerja Karyawan Pada PT. Hyundai Mobil Indonesia Cabang Kalimalang," Jurnal Techno Nusa Mandiri, Maret 2017.

[9] F. Fitriyani, "Penerapan Metode Profile Matching Dalam Sistem Pendukung Keputusan Untuk Penentuan Kelayakan Dari Bso Menjadi Ukm (Studi Kasus Senat Mahasiswa Universitas Amikom Yogyakarta)," Intechno, vol. 1, pp. 11-14, November 2018.

[10] J. Banjarnahor, "Penerapan metode profile matching dalam sistem pendukung keputusan penilaian kinerja karyawan(Studi Kasus : PT Jaya Prima Plastik)," Riset dan E-Jurnal Manajemen Informatika Komputer, vol. 5, Oktober 2020.

[11] Y. Malau, "Sistem Pendukung Keputusan Pemilihan Kategori Promosi Produk Menggunakan Metode Profile Matching," MATRIK, vol. 19, pp. 339346, 2020.

TRANSFORMATIKA Vol. 19, No. 1, July 2021: $74-83$ 
[12] E. Pawan, "Implementasi Metode Profile Matching untuk Menentukan Penerima Beasiswa Bidikmisi," Citec Journal, vol. 8, pp. 54-63, Januari 2021.

[13] D. P. Sari, "Pemilihan Karyawan Terbaik Dengan Metode Profile Matching," JURNAL J-CLICK, pp. 138-147, Desember 2020.

[14] D. N. Sholihaningtias, "Sistem Pendukung Keputusan Kenaikan Jabatan Menggunakan Metode Profile Matching," Jurnal String, vol. 2, pp. 282-288, April 2018.

[15] E. Sutinah , "Sistem Pendukung Keputusan Menggunakan Metode Profile Matching Dalam Pemilihan Salesman Terbaik," Informatics For Educators and Profesionals, vol. 2, pp. 29-42, Desember 2017. 